Tattva, Vol. 3, No. 2, July - December 2011, pp. 1-10

ISSN0975-332X | https://doi.org/ 10.12726/tjp.6.1

Tattua

JOURNAL OF PHILOSOPHY

\title{
ONE AND MANY: A TEST-CASE FOR WHITEHEAD'S METAPHYSICS FOR SOUTH ASIAN PHILOSOPHY
}

\author{
Robert Cummings Neville
}

\begin{abstract}
:
Unlike John Cobb, Jr, and others, I argue that the problems of pluralism cannot even be formulated accurately without a far more complicated theory of religions than usually functions in the pluralism discussions. A theory of religious worldviews is sketched that shows that religious symbols need to be interpreted along the lines of five continua: from the ultimate to the proximate, from the sophisticated to folk religion, from explicit values to implicit functioning values, from tight determination of life to loose determination, and from deep commitment to light commitment. In different context, given symbols for religious engagement, including intellectual ones, mean different things on different points within each of these continua. The paper strongly supports the process defense of metaphysics as necessary for comparing worldviews, although it rejects the process theological conception as not being able to deal with the ontological problem of the one and the many, which is so important in any religion.
\end{abstract}


While I do not doubt that there is something true and religiously enlightening about all the religions that have survived in several social contexts and developed a multigenerational literature, I do doubt that the way to recognize and appreciate this is with a strategy of assigning different parts of the ontological pie to different religions. John Cobb has argued that a metaphysical system such as Whitehead's articulates more than one ultimate reality, and that different religions orient themselves to different ultimates. David Griffin calls this "complementary pluralism," meaning that the religions complement rather than contradict one another, which can be seen from the perspective of the metaphysical system.' Without suggesting too much similarity between Cobb's (and Griffin's) position and that of S. Mark Heim, Heim himself has developed a widely discussed complementary pluralism in Salvations: Truth and Difference in Religion, ${ }^{2}$ although he does not avail himself of a metaphysical system.

I myself think that a better strategy than complementary pluralism for recognizing and appreciating religious diversity derives from the following observation. Reality is what it is and all major religions have to address all or most of its important parts in one way or another. These parts include what the religions believe to be ultimate, but also much more. The ultimate bears upon human social and personal life in a great many dimensions, and all these dimensions of ultimacy are religious realities to which every religion needs to respond somehow. Included among these dimensions of ultimacy are general traits of the human condition, predicaments that religious salvation or virtuosity is supposed to redress, the nature of that redress itself, including spiritual practices and beliefs having to do with salvation or virtuosity, ways of living through daily life that are determined in part by special comportments toward ultimate matters, and ways of handling crises when religions' sacred canopies prove inadequate to the task.

To defend the thesis that every multi-contextual and multi-generational religion has to respond to all, or at least very many, of the religious dimensions of reality, it is necessary to defend a metaphysical view of the world. In this I am in strong

1 See Griffin's essays "Religious Pluralism: Generic, Identist, and Deep" and "John Cobb's Whiteheadian Complementary Pluralism" in his edited volume, Deep Religious Pluralism, Louisville, KY: Westminster/John Knox, 2005, 3-66.

2 See S. Mark Heim, Salvations: Truth and Difference in Religion, Maryknoll, NY: Orbis, 1995 and also his The Depth of the Riches: A Trinitarian Theology of Religious Ends, Grand Rapids, Ml: Eerdmans, 2001. 
agreement with John Cobb and the whole process tradition, as well as John Hick, Thomists, and Perennialists, although there is little agreement on the best metaphysics. The metaphysics to be defended has to be defended on its own terms, which include but are not exhausted by its adequacy for interpreting religious matters. The affirmation of metaphysics distinguishes the approaches to pluralism just mentioned from those arising out of some kind of phenomenology of religion, including Heim's, which think to avoid inquiry into what reality is to which religions need to respond. I think that metaphysical inquiry cannot be avoided but should be embraced, as it has been by all the great religious traditions in one form or another.

Instead of seeing religions as complementary in orienting themselves to different ultimates and dimensions of ultimacy, my hypothesis is that we should acknowledge that all religions have ways of orienting themselves to all the ultimates and ultimate dimensions. For instance, in all religions there is a spectrum of ways of symbolizing or addressing ultimacy that runs from very anthropomorphic conceptions and stories to very abstract principles. In Hinduism, for instance, ultimate divinity is symbolized by a dancing cowherder seducing maidens, and by a seated elephant-man representing wisdom, and also by Isvara, creator of the world, Saguna Brahmanthe ultimate with the qualities of ultimacy, and Nirguna Brahman-the ultimate beyond qualities even of ultimacy. Some Buddhists worship Avaloketeshvara so as to attain health and a good love-life while at the same time believing that ultimately there is no self to be healthy or lasting body to be erotically pleasured. In Christianity, God is represented as a supernatural personal player in a cosmic narrative, and at the same time is the One beyond being and non-being, the pure Acl of Esse, the indeterminate ground of being. In Chinese religion the ultimate is expressed in the virtues of the ancestors and the gods of the kitchen, and also as Heaven and Earth, Principle and Material Force. The point is that there must be something in reality that requires anthropomorphic representations of ultimacy and something else, perhaps many things, that requires representation in transcendent principles that approach indeterminacy. If a religion has engaged reality densely, it will have to deal with both sides, or rather with a spectrum of representations. The metaphysical account of reality that can articulate this might be the one favored by process philosophers, namely that one ultimate, requiring anthropomorphic representation, is the process-God while another ultimate, requiring transcendent indeterminacy, is creativity in Whitehead's sense. I myself prefer a different metaphysical theory, to which I shall return shortly.

But the point here is that every religion has both sides in various representations. It is not the case that Hinduism is mainly oriented to transcendent indeterminacies that can be explicated metaphysically through the Whiteheadian Category of the Ultimate and that Christianity is mainly oriented to a personal deity whose 
metaphysical expression is the dipolar process God. Hinduism has both sides, and many intermediate representations, and so does Christianity. They are not complementary with regard to ultimate matters, but rather differ in the specifics of their symbolizations.

II.

Permit me to present a more formal hypothesis about religious pluralism that puts my remarks so far in a broader context. The cultures of the world have a plurality of worldviews. Those aspects of a worldview having to do with ultimacy are its religious aspects. We can speak of religious worldviews when considering the religious aspects of worldviews so long as we keep in mind that worldviews are formed by additional dimensions over and above those relating to ultimacy, for instance by science. The hypothesis I propose about worldviews is this. A worldview is a cultured set of signs for orienting intentional behavior that has five spectra of symbolic engagement each of which needs articulation and analysis. ${ }^{3}$ The five spectra are those of "scale," "sophistication," "valuation," "identity," and "commitment." Let me briefly characterize each of these.

The spectrum of scale runs from symbolic engagements of ultimacy to symbolic engagements of proximate behavior and belief. The symbolic engagements of ultimacy fall into what Peter Berger characterized as sacred canopies. Many kinds of sacred canopies exist, including metaphysical ones, and often we tend to identify religious worldviews with those ultimate or world-defining symbolic structures. But at the proximate end of the worldview's scale, the symbolic structures tell us when to wash our hands, how to handle purity/impurity matters, when to pray and about what, how to defer to people and nature, when to have babies, and when to go to war. The symbolic structures at various points along the spectrum of scale might not be consistent with one another, or even commensurable; yet they are connected within the worldview in ways that need analysis.

The spectrum of sophistication has philosophy at one end and folk culture at the other, each with its symbolic structures. This spectrum crosses the scale spectrum at every point. So, within a worldview there is a metaphysical representation of the sacred canopy and also a folk-culture representation of the sacred canopy. At the proximate end of the scale spectrum there is a philosophical/scientific/ethical

3 This definition and the sketch to follow are detailed in my "Worldviews," in American Journal of Theology and Philosophy, 30/3 (September 2009), 233-43. 
representation of daily practices as well as a folk-culture representation. Just as the scale spectrum has intermediate positions that combine or confuse ultimate and proximate symbolic representations, so the sophistication spectrum has intermediate positions that are more or less philosophical as well as more or less functions of folk-culture.

These observations about the scale spectrum and the sophistication spectrum lift up the point that a worldview is not a consistent set of symbols, like a theory is supposed to be. Rather it is a congeries of symbolic systems that function together so that the worldview engages the realities with symbols positioned all along each of the spectra. This raises important questions for analysis. To recur to our previous example, is the fact that all religions have both anthropomorphic and highly transcendent symbols of ultimacy a function of realities articulated at the ultimacy end of the scale spectrum? Or is it a function of the needs of the sophistication spectrum for both philosophical and folk-culture symbolic engagements? That is not an easy question to answer without a detailed empirical analysis of the symbol systems at hand, and the answer is probably that the anthropomorphic/ transcendence tension is a function of both spectra in different respects.

The spectrum of valuation runs from values that are articulated and objectified in a worldviews symbol system to values that are functionally efficacious in the worldview but are implicit and not articulated and objectified. The implicit values are those that guide the way by which people living with the worldview engage the world because of the very structure of their symbolic engagements, regardless of what the symbols seem to say about values. Most contemporary multi-contextual and multigenerational religions, for instance, have a dual and contradictory set of values. On the one hand is an Axial Age articulation of values, such as that one should be compassionate and just to all people, not just to those within one's ingroup. On the other hand the same worldviews also engage the world from an ingroup point of view: ask a Jew about the operative values in Christian love, for instance. The articulated value of universal love is no less real than the implicit offen contradictory value of ingroup loyalty, but it functions in a different way, as an ideal rather than an impulse-guide. The spectrum of valuation cuts across all the points on both the spectrum of scale and that of sophistication.

The spectrum of identity has to do with the extent to which a given worldview determines the identity of an individual or group holding the worldview. At one end of the identity spectrum, the worldview very closely defines an individual or group's identity, and at the other end of the spectrum people have their identities determined by many things in addition to the worldview, and the worldview's symbols for engagement are rather vague. It is not that the people with minimal worldview 
identity necessarily have a different worldview from one that is identity-intense for others; it is that they define their identities in large measure apart from the worldview they hold.

Related to this but not the same is the spectrum of commitment. An individual or group can be deeply committed to a worldview, or, at the other end of the spectrum, people can be lightly committed, and ready to take up another worldview if one comes along, or ready to entertain a number of worldviews. All along the commitment spectrum the worldviews also exhibit the spectrum of identity, with people being maximally or minimally committed to a worldview that determines their identity thickly, and others committed maximally or minimally to a worldview that only vaguely determines their identity.

The upshot of this hypothesis about worldviews, if it has merit, is that religions are far more complex than appears in most discussions of religious pluralism. A religion is the religious dimension of a worldview; or rather it is a family of religious dimensions of related worldviews. Until we have a complex understand of a religion's worldview, that is, the assemblage of symbols by which the religion cultivates the engagement of the ultimate dimensions of reality, we do not know what we are comparing when we say that religions are the same or different. Commitments about ultimate reality in the sacred canopy are part of the story, but process philosophy is too hasty to say that this is what makes diverse religions similar or complementary. Commitments about proximate practices are also part of the story, but anthropologists are too hasty to say that comparative ritual behavior, for instance, is the main determinant of religious boundaries. Folk-culture practices are part of the story, but so are the philosophical and scientific theories. Conceptions of salvation are part of the story, but not the whole. I could go on and on about the multifarious symbol systems that function within religions along the five spectra discussed. The point is clear, however: the identification of a religion is extremely complex and religions need to be identified before questions of pluralism, inclusivism, or exclusivism can be raised. Any religious worldview has symbol systems that are not univocal and that cannot be expressed in any one symbolic language, yet which resonate with one another. When the resonance in religious life is harmonious, the worldview has a consistency that still cannot be expressed univocally. When the resonance is inharmonious, the worldview contains within itself serious contradictions, but can function as a life-guiding worldview nonetheless.

III.

Behind all of my argument so far is the conviction, which I have defended in many places, that symbols make possible the engagements of ultimacy in all its dimensions 
that we call religious. ${ }^{4}$ Symbols articulate our engagements, giving us discriminations so that we interpret the realities symbolized in the respect in which those symbols stand for the realities. Engagement is always interpretive, but it is also active. Some engagements are episodic, others are repetitive, and yet others take years. Whereas the symbol systems that guide engagements might not be consistent with one another, the engagements might be consistent, in which case we have a consistent religious life. Nothing should make us think that religions are always consistent. The periodic adventures in defining orthodoxy and orthopraxy should tell us that religions are often inconsistent, but no less powerful for engaging us with ultimacy in its many dimensions.

Whereas it is one thing to note that a set of symbols fosters genuine engagement with ultimate realities, it is another thing to determine whether that engagement is true or false, authentic or in denial, good or bad. The determination of the truth question requires triangulating on specific engagements to see whether and how their symbolically shaped interpretations pick up on what is important and valuable in their objects so that the interpreters register that and engage appropriately. There is no reason to think that the assemblages of engagements in any one nameable religion are equally true or false; because engagements are always context-dependent, the symbols that guide engagements might be true in one context and false in another. Practitioners of a religion would hope that their engagements are true as well as engaging, but need to work to make sure it turns out that way as much of the time as possible. The identity of a religion, however, is in how it engages, both truly and falsely, and in what contexts.

To raise the question of religious pluralism requires more preparatory work than the conversation over the last thirty years has given. First of all, we cannot tell whether religions are in agreement or disagreement, overlap or are mutually incommensurate, until we have comparative categories that are as neutral and unbiased as possible. This means engaging in scholarly projects that explicitly develop good comparative categories that are the result of disciplined accountability to a variety of members or participants in the religions to be compared, to the natural and social sciences, and philosophies, that provide information and methods of analysis, to virtuosi in comparative dialectic, and indeed to anyone with an interest in the outcome of comparison. ${ }^{5}$ Although progress has been made, we are far from being able to identify our religions in sophisticated ways. The discussion of pluralism often takes vague tokens, such as the "names" of religions-Hinduism, Christianity, Daoism,

4 See, for instance, my The Truth of Broken Symbols, Albany, NY: State University of New York Press, 1996, and On the Truth and Scope of Theology, New York, NY: T \& T Clark, 2006.

$5 \quad$ argue in detoil for this point in On the Truth and Scope of Theology. 
and Buddhism, etc.- - to provide identity. The differences between these names, however, refer only to superficially distinct histories of symbol systems. Commitment to religions "as named" all too often results in political polarization when in fact the worldviews of the different religions might have very great overlap. The boundaries of different religions are drawn differently according to each of the spectra for the analyses of worldviews. The specification of this is an enormously complicated empirical project. We are only beginning to develop the comparative categories that make it possible and feasible.

Another part of the preparatory work for addressing pluralism is to understand symbolic engagement and what this means for religion. Comparison of different doctrines is relatively superficial. So is comparison of rituals, spiritual practices, and so forth. Only when these and other religious elements are integrated can we see what goes into a given symbolic engagement of ultimacy. Too long the discussion of religious pluralism has been about the truth of theological claims rather than the truth of concrete engagements.

\section{IV.}

My argument here has been that there is a better alternative than the comparison of explicit conceptions of the ultimate for identifying and comparing, with evaluation, different religions. But let me return to a metaphysical moment to engage process philosophy's approach to pluralism. The depiction of religious worldviews that I have given represents them as assemblage of diverse symbol systems. The obvious question to ask is how they are unified. Or are they unified? What kinds of unity and disunity, harmony and disharmony, can be sustained in functional worldviews that engage ultimate realities? This is an important version of the problem of the one and the many.

Whitehead's conception of the metaphysical unity of many things is a logical notion, as when God prehends a multiplicity of actual occasions and integrates them logically by means of the infinite conceptual capacity of the divine primordial nature. Finite occasions also give logical definiteness to what they prehend, albeit with considerable loss. According to the Category of the Ultimate, any achieved unification immediately creates a new thing which then sparks another process of unification. Logic, or the consistency of eternal objects, is not the whole of the ontological reality, which is why Whitehead's is a process philosophy. Yet the creative advance into novelty moving beyond actualized logical unity is a multiplicity. What is the ontological unity of creativity plus unifying creatures? It cannot be first one and then the other, for time itself is multiple. It cannot be actualized unity, because that does not exhaust creativity. Nor can it be creativity itself as the advance into novelty 
unifying a prior multiplicity, because creativity needs to be added to finished, once creative occasions. As Whitehead pointed out about the ontological principle, any multiplicity or complexity needs to be understood in terms of the actual decisions that have given rise to it. When it comes to the multiple determinate ultimates, such as God and creativity in Whitehead's system, eventually there has to be one decisive act that creates them together as determinate with respect to one another and yet genuinely different so as to be irreducible to one another. That decisive act, which is ontologically primitive so as to give rise to the ultimate determinate "first principles" of things, is not temporal, because time is determinately multiple, but rather eternal. Whiteheadian creativity is creativity within the cosmos, defining temporal advance in relation to achieved logical unity. This cosmological creativity is different from ontological creativity, which is wholly indeterminate in itself but determinate in giving rise to anything determinate. ${ }^{6}$

From a religious point of view, process theology stumbles over the problem of the one and the many with respect to persons. As a society of actual occasions, a person combines both the objective definiteness of achieved concreteness as well as the subjective creativity of concrescence. According to Whitehead and many of his followers, God prehends only the objective definiteness, and the subjective concrescence passes away. In this case, there is no unity of the subjective and the objective sides or moments of the person. According to others, such as Mariorie Suchocki, God prehends the subjective concrescence as well as the objective definiteness, so that a kind of ongoing subjective immortality takes place within the life of God.' But then there is no real exteriority of persons to the actual consequent nature of God and the multiplicity becomes what Peirce would call "degenerate secondness," difference reduced to the idea of difference. There is no easy solution to this problem because the process solution to the problem of the one and the many by means of the Category of the Ultimate is too superficial to get at real ontological difference and harmony. ${ }^{8}$

- For a variant process approach to the problem of the one and the many, see Joseph $A$. Bracken, S.J.'s, The One in the Many: A Contemporary Reconstruction of the God-World Relationship, Grand Rapids, Ml: William B. Eerdmans, 22001.

7 See the discussions, for instance, in World without End: Christian Eschatology from a Process Perspective, edited by Joseph A. Bracken, S.J., Grand Rapids, Ml: William B. Eerdmans, 2005.

8 On this point, see the exchange between David Griffin and me in his Whitehead's Radically Different Postmodern Philosophy: An Argument for Its Contemporary Relevance, Albany, NY: State University of New York Press, 2007, chapter 9, and my "A Letter of Grateful and Affectionate Response to David Ray Griffin's Whitehead's Radically Difference Postmodern Philosophy: An Argument for Its Confemporary Relevance, in Process Studies 37/1 (SpringSummer 2008), 7-38. 
Coming to terms with South Asian approaches to the problem of the one and the many can cause us to ask about our metaphysical theories anew. A persistent theme in much South Asian thought, although of course not in all, is that determinate difference is made possible by something more basic. Mind without content makes possible different ideas or images in mind. Behind Isvara the creator is Saguna Brahman who makes creation possible and behind Saguna Brahman is Nirguna Brahman, whose absolute indeterminacy is the condition for all determinate traits, including those of Saguna Brahman, to be possible. In these and similar motifs of thought, determinate ultimates are understood to be contingent on something (or no-thing) wholly indeterminate. Schools of South Asian thought differ among themselves in many fascinating ways as to how real or illusory the determinate things are that constitute the multiplicity of experience and desire.

My thought about process philosophy is that its solution to the problem of the one and the many does not allow for the registration of this dialectic of views within South Asian religions. Process thought requires too much determinateness, and limits the indeterminate to the future. A better metaphysics is needed to account for fecund indeterminacy. The strength of process thought in connection with South Asian religions and philosophies is its insistence on metaphysics, and its demonstration from esse to posse of the possibility of metaphysics. 